\title{
Modelling household water use: Using empirical data to inform continuous simulations
}

\author{
$\underline{\text { D. Leonard }}^{\text {a }}$ and S. Gato-Trinidad ${ }^{\text {a }}$ \\ ${ }^{a}$ School of Engineering, Swinburne University of Technology, Hawthorn, Victoria \\ Email: dleonard@swin.edu.au
}

\begin{abstract}
In recent decades traditional water management practices have come under stress from rising global populations and changing climate conditions. The prohibitive costs of upgrading centralised infrastructure networks to meet these changing conditions has encouraged research into the provision of integrated water management at the site scale, such as rainwater harvesting (RWH) or greywater re-use. Unfortunately, effective design, implementation and optimisation of these strategies has been restricted by uncertainties when quantifying how these systems will perform on each site. The reason for this difficulty is that there are many aspects of household or site scale hydrology that are poorly understood or difficult to model, including residential outdoor water use and garden watering. The accuracy and speed at which these aspects of site hydrology can be modelled is a vital consideration in the development of site scale water management.
\end{abstract}

This study aimed to improve the understanding surrounding the accuracy and usability of different strategies for modelling the interaction between the different household water uses. This will provide insight into how their effect upon site scale hydrology can be quantified in future studies and improve the design and optimisation of new integrated water management strategies. This was achieved by analysing four different strategies that each apply different assumptions to account for the three main end uses of household water use (indoor, garden watering and other outdoor water uses) that have been utilised or suggested by previous researchers for use within continuous/water balance simulations. These four strategies were each tested using historic water use data from 100 residential properties in Melbourne's eastern suburbs.

The 'lowest average water use' strategy assumed that no outdoor water use occurred during the month with the lowest average daily water use and that any variation from this value would be caused by outdoor water use. This strategy calculated a consistent indoor water use of 83.9 L per person per day with separate variable garden watering and other outdoor water use values that can be averaged across multiple years to find the average values per month. This method appeared to be promising as it was easy to use and returned results that were mostly logical. However the assumption that indoor water use is constant across the year should be questioned.

The 'wet or dry averages' and 'consecutive dry days' strategies both assumed that no outdoor water use would occur on days with rainfall and that any increase on days without rainfall would be caused by outdoor water use with possible reference to the number of consecutive days without rainfall. While these strategies were able to demonstrate that water use is lower on days with rainfall, and increases on days without rainfall, quantifying these findings produced illogical garden watering estimates. Daily indoor water use was calculated as $115.3 \mathrm{~L}$ per person with variable, and sometimes negative outdoor and garden watering values. It appears likely that either indoor water use did not remain consistent or outdoor water use did occur on days with rainfall.

The 'identifying peak usage' strategy was based upon the assumption that garden watering occurs a limited number of times each week and could therefore be identified by examining the higher water use values from each week. This strategy analysed garden watering only and did not attempt to separate indoor water use from non-garden based outdoor water uses. This strategy identified a gap between the higher daily water use values from properties with and without garden watering during some seasons. With the average property watering their garden twice a week using a combined total of 82.1 L per person during autumn and 59.3 L per person during spring. No garden watering was detected during summer or winter (the summer results may have been caused by an unusually wet summer or by missing data for some seasons from some properties).

Comparing the merits of these four strategies the 'lowest average water use' was the easiest to use, quickly providing logical results for both garden watering and other outdoor water use that were easy to visually interpret. Unfortunately the accuracy of this method relies upon the assumption of consistent indoor water use and this must be questioned. The 'identifying peak usage' strategy was more computationally difficult but returns a more realistic assessment of the water demand imposed by garden watering, including a weekly garden watering pattern. However this strategy could not separate indoor and other outdoor water uses. The selection of which strategy is preferable will therefore depend upon the needs of the individual study. By being aware of the different strengths and weaknesses that have been identified in this study, future designers will be better equipped to select the best strategy for their individual needs when working with site scale hydrology

Keywords: Household water use, garden watering, seasonal variation, continuous simulation 
Leonard and Gato-Trinidad, Modelling household water use: Using empirical data to inform continuous simulation

\section{INTRODUCTION}

In recent decades rising populations and uncertain future climate patterns have driven international recognition of the importance of sustainable water management (Amos et al. 2018). As these trends accelerate the redevelopment of existing catchments, it is no longer considered economical to upgrade existing centralised water management networks to keep pace with these changes (Burns \& Mitchell 2008). The integration of site scale management and source control strategies, such as rainwater harvesting (RWH), can be used to keep pace with these ongoing changes (Coombes et al. 2011).

To effectively and efficiently integrate these site scale initiatives requires a detailed understanding of how they will interact with the hydrology of the individual sites (Bradford et al. 2008). This is frequently achieved through the use of continuous simulations (also known as water balance simulations or behavioural analysis) to model the interaction of water supply, demand and site storage on small catchments over a historic time period (Roebuck \& Ashley 2006). This approach benefits from being simple to use and easy to adapt (Campisano et al. 2017) and these are essential qualities when attempting to analyse a subject as numerous and as variable as residential property lots (Akan 1985). The weakness of these simulations is that they are only as accurate as the assumption used in their creation (Campisano et al. 2017). Unfortunately estimating household water use, especially outdoor water use and garden watering for residential properties is notoriously difficult (Amos et al. 2016). The question facing designers is how to account for these elements without compromising the ease of use that characterises the model.

This study aims to explore this issue by applying a range of simplified, continuous simulation friendly, household water use estimation strategies to an empirical water use data set to qualify accuracy and confirm their usability. These findings should be of use to researchers who are considering their options when planning to construct their own continuous water balance simulations for residential sites.

\section{BACKGROUND}

The empirical water use data that was utilised during this study was originally collected by Yarra Valley Water (YVW), one of the three water supply authorities that service the eastern suburbs of Melbourne, Australia. This data was collected primarily for a residential study by YVW where 100 households were logged and water use monitored at a 5 second time intervals for a period between 2010 and 2012 (exact monitoring periods vary between properties). This was accompanied by a household water use survey that captured households' water use characteristics including the current household occupancy, water appliances, lawn/garden areas and the presence or absence of any RWH systems. This study used a condensed, hourly-time step, version of this data that was provided to Swinburne University of Technology for modelling studies or research purpose. For confidential reasons, the identities of the 100 households were removed.

\section{METHODOLOGY}

A review of the existing literature was undertaken to identify current strategies for estimating household water use during continuous simulations. From this review the following four strategies were identified as having been either used or suggested in previous studies. This study tested each of these water use estimation strategies using the YVW water use data. A description of each of these strategies and how they were tested using the supplied data is as follows:

\subsection{Lowest average water use}

The 'lowest average water use' strategy attempts to separate indoor and outdoor water use based upon variation across a range of time based water use averages (e.g. monthly averages). This strategy assumes that the lowest of these time based averages is caused solely by indoor water use with no outdoor water use present during that period. This indoor water use is assumed to be consistent across the length of the analysis and any variation from this value has been caused by outdoor water use (Gato et al. 2007; Burns et al. 2012). The legitimacy of this strategy is based upon two widely used assumptions, that variation in outdoor water use is frequently seasonal (Jensen et al. 2010) and that indoor water is non-seasonal (Knights et al. 2012).

By analysing the annual variation in properties without garden watering, the variation due to the other outdoor water uses (those other than garden watering) can be identified. This information can then be compared against the water use from properties with garden watering to determine the variation caused by garden watering. Assuming that there is no outdoor water use of any kind during the lowest average, the water use during this period should be equal between the properties with and without garden watering.

\subsection{Wet or dry averages}

The 'wet or dry averages' strategy attempts to separate the indoor and outdoor components from the average water use at a property by analysing the daily rainfall values at the site. This strategy is based upon the assumption that outdoor water use does not occur on days with precipitation (Bradford et al. 2008) while indoor 
Leonard and Gato-Trinidad, Modelling household water use: Using empirical data to inform continuous simulation

water use is unaffected by daily rainfall (Gold et al. 2010). By separately applying this strategy to properties with and without garden watering, the effect of garden watering can be separated from the other outdoor water uses.

The days with and without rainfall were identified by comparing the recorded water use figures from each property against local rainfall data. This data was obtained from the Australian Bureau of Meteorology (2019) for the 8 weather stations closest to the towns identified in the household water use survey. These stations recorded rainfall data on a daily time step with each day containing the rainfall total for the 24 hours preceding 09:00. To facilitate comparison with the YVW data the daily water use averages were recalculated to match this definition of a day.

\subsection{Consecutive dry days}

The 'consecutive dry days' strategy is an extension of the 'wet or dry averages' theory that states that outdoor water use increases as the time since the last rainfall event increases (Amos et al. 2018). Since this strategy assumes that indoor water use will remain unchanged by the length of the preceding dry period, any variation over this period must be caused by outdoor water use. By separately applying this strategy to properties with and without garden watering, the effect of garden watering can be separated from the other outdoor water uses.

\subsection{Identifying peak usage}

The 'identifying peak usage' strategy attempts to quantify the magnitude and frequency of garden watering by identifying repeated high values in recorded water use. This method is based upon previous empirical research that identified that the average property will only water their gardens a certain number of times a week (GatoTrinidad et al. 2011) combined with the assumption that indoor water use is more consistent than outdoor water use (Knights et al. 2012). To test this method it will be necessary to determine if it is possible to clearly identify the peak water use values that represent the presence of garden watering within the recorded water use data. This method does not separate indoor water use from non-garden watering outdoor water uses.

\section{RESULTS AND DISCUSSION}

\subsection{Lowest average water use}

To test the 'lowest average water use' strategy the average daily water use values were calculated for each month for each property with and without garden watering (Figure 1). These averages were calculated on a monthly basis to facilitate the ease of calculation but the same process could be applied at different time steps.

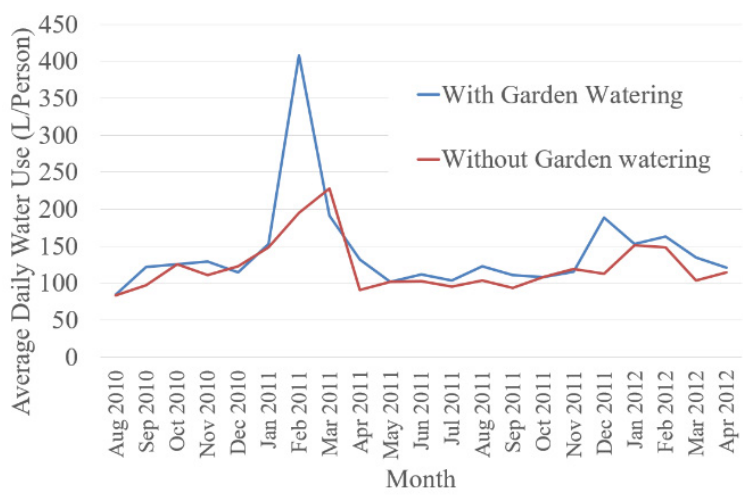

Figure 1. Monthly variation in per person water use.
From Figure 1 it can be seen that the lowest average daily water use for properties without garden watering was $83.9 \mathrm{~L}$ per person per day (August 2010). Since this is assumed to be the consistent and non-seasonal indoor water use value, all variation between this value and the monthly water use values from these properties can be assumed to be caused by the outdoor water uses other than garden watering. Once these values are known the variation in water use due to garden watering can be found by applying these two known values to the properties with garden watering. The results are displayed in Figure 2.

From Figure 2 it can be seen that the 'lowest average water use' strategy has produced results that appear logical, with outdoor water use is higher during summer and lower during winter. It must be noted that garden watering usage during March 2011 was calculated as negative. This could have been caused by abnormal climate conditions or variation in the indoor water use values but it must be noted that this occurred during a period of significantly increased other outdoor water use. It is therefore possible that this discrepancy occurred when properties that did not normally water their gardens (and therefore did not report garden watering on their water use survey) chose to undertake some gardening, possibly in response to abnormal climate conditions. Since not all properties involved in the study were metered for the full duration it is also possible that variation has been added as properties entered and left the study. The considerable difference between the two summer peaks would also indicate variability between years. 
Leonard and Gato-Trinidad, Modelling household water use: Using empirical data to inform continuous simulation

These findings (Figure 2) can be then be consolidated into a set of monthly averages that can be used when modelling household water use. These averages are displayed in Table 1 where it can be seen that the averaging process has reduced the magnitude of the extreme values displayed.

Unfortunately the accuracy of this strategy relies upon the assumption of consistent, nonseasonal indoor water use and this cannot be determined from this data set. When viewing Figure 1 it can be seen that the properties without garden watering still faced significant seasonal variation in water use. This concern

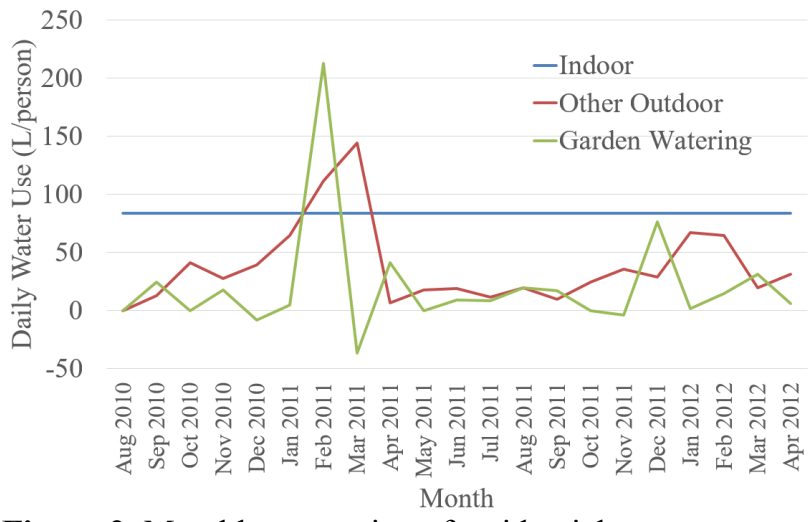

Figure 2. Monthly separation of residential water use. is shared by other studies that have identified seasonal trends in some indoor water uses, such as increased numbers of showers during summer (Gato-Trinidad et al. 2011).

Table 1. Monthly average breakdown of household water use.

\begin{tabular}{lrrrrrrrrrrrr}
\hline \multicolumn{1}{c}{ Average Daily } & Water Use (L/ Person/ Day) \\
Water Use & \multicolumn{1}{c}{ Jan } & \multicolumn{1}{c}{ Feb } & \multicolumn{1}{c}{ Mar } & \multicolumn{1}{c}{ Apr } & May & Jun & \multicolumn{1}{c}{ Jul } & Aug & Sep & Oct & Nov & Dec \\
\hline Indoor & 83.9 & 83.9 & 83.9 & 83.9 & 83.9 & 83.9 & 83.9 & 83.9 & 83.9 & 83.9 & 83.9 & 83.9 \\
Other Outdoor & 66.0 & 88.1 & 82.0 & 18.9 & 17.9 & 19.3 & 11.7 & 9.9 & 11.3 & 32.9 & 31.5 & 33.9 \\
Garden Watering & 3.1 & 113.8 & -2.8 & 23.6 & 0.1 & 9.1 & 8.2 & 9.7 & 20.9 & -0.1 & 7.0 & 34.0 \\
\hline
\end{tabular}

\subsection{Wet or dry averages}

To test the 'wet or dry averages' strategy the household water use from days with and without rainfall were separated. The results are displayed in Table 2 for a range of different property site conditions. From Table 2 it can be seen that that there was a significant increase in water use on dry days within all sub categories. By comparing the relative water use values from Table 2, the breakdown of average property water use was calculated (Table 3).

Table 2. Average water use on days with or without rainfall.

\begin{tabular}{llllll} 
& $\begin{array}{l}\text { Wet Days } \\
\text { L/Person } \\
\text { Sub Category }\end{array}$ & $\begin{array}{l}\text { Standard } \\
\text { Deviation }\end{array}$ & $\begin{array}{l}\text { Dry Days } \\
\text { L/Person } \\
\text { /Day }\end{array}$ & $\begin{array}{l}\text { Standard } \\
\text { Deviation }\end{array}$ & $\begin{array}{l}\text { Difference } \\
\text { L/Person } \\
\text { /Day }\end{array}$ \\
\hline All Properties & 117.8 & 61.7 & 133.6 & 95.5 & 15.8 \\
Garden Watering & 118.9 & 69.0 & 133.6 & 108.2 & 14.7 \\
No Garden Watering & 115.3 & 42.2 & 133.5 & 59.5 & 18.1 \\
Garden Watering (no RWH) & 117.0 & 69.7 & 129.6 & 83.7 & 12.6 \\
No Garden Watering (no RWH) & 124.0 & 47.0 & 141.7 & 66.6 & 17.7 \\
Garden Watering (RWH) & 120.1 & 69.4 & 136.3 & 123.2 & 16.2 \\
No Garden Watering (RWH) & 94.2 & 12.9 & 113.4 & 31.8 & 19.2 \\
\hline
\end{tabular}

From Table 3 it can be seen that the per person water use ascribed to garden watering varies greatly between the different property configurations and even displays negative values when RWH is not present. This appears illogical, but the reason can be identified in Table 2, where there is a noticeable difference between the water use of properties with and without garden watering during wet days when no outdoor water use was assumed

Table 3. Separation of indoor, outdoor and gardening water use using the 'wet or dry averages' strategy.

\begin{tabular}{llll} 
& \multicolumn{3}{l}{ Water Use (L/ Person/ Day) } \\
Sub Category & Indoor & Other Outdoor & Gardening \\
\hline With RWH & 94.2 & 19.2 & 22.9 \\
Without RWH & 124.0 & 17.7 & -12.1 \\
All & 115.3 & 18.1 & 0.1 \\
\hline
\end{tabular}

days as recorded rainfall; or b) the indoor water use was not as consistent as assumed. It is also interesting to note the higher standard deviation between the average water uses from the different properties with garden watering (Table 2). This would indicate that garden watering is significantly more variable than the other household water uses. 
Leonard and Gato-Trinidad, Modelling household water use: Using empirical data to inform continuous simulation

\subsection{Consecutive dry days}

The 'consecutive dry days' strategy assumes that outdoor water use is dependent upon the time that has elapsed since the last rainfall event. To test this strategy the 'wet or dry average's analysis was repeated with the distinction of the number of dry days preceding each water use value added into the examination. The results of this analysis (see Table 4) show that although water use increased steadily as the number of days since the

Table 4. Average water use after consecutive days without rainfall

\begin{tabular}{lllllll}
\hline & Water Use & \multicolumn{4}{c}{ Number of Consecutive Dry Days } \\
Sub Category & (L per Person) & 0 & 1 & 2 & 3 & $4+$ \\
\hline \multirow{2}{*}{ With RWH } & Indoor & 94.2 & 94.2 & 94.2 & 94.2 & 94.2 \\
& Other Outdoor & 0.0 & 10.3 & 5.6 & 25.9 & 29.1 \\
& Garden Watering & 25.9 & 18.5 & 30.0 & 20.2 & 24.1 \\
Without RWH & Indoor & 124.0 & 124.0 & 124.0 & 124.0 & 124.0 \\
& Other Outdoor & 0.0 & 1.9 & 5.9 & 23.9 & 30.7 \\
& Garden Watering & -6.9 & -8.8 & 0.0 & 6.0 & 20.6 \\
\hline
\end{tabular}

last rainfall event increased, many of the estimated garden watering values were either illogical or counter to the initial assumptions. This would imply that the assumption of there being no outdoor water use on days with rainfall is in error. This would explain

why the indoor water use assumptions in the 'consecutive dry days' and 'wet or dry averages' strategies are higher than the indoor water use estimated by the 'lowest average water use' strategy (Table 1).

Table 5. Standard Deviation in water use averages (L per Person) after consecutive days without rainfall

Property Characteristics Number of Dry Days

\begin{tabular}{lllllll} 
RWH & Gardening & 0 & 1 & 2 & 3 & $4+$ \\
\hline Yes & Yes & 69.4 & 85.3 & 99.4 & 149.4 & 154.3 \\
& No & 12.9 & 43.3 & 20.4 & 45.5 & 38.5 \\
No & Yes & 69.7 & 60.9 & 80.7 & 91.0 & 97.4 \\
& No & 47.0 & 48.8 & 51.2 & 106.9 & 78.2 \\
\hline
\end{tabular}

This would indicate that the variability of water use from properties with garden watering becomes increasingly variable as the length of the preceding dry period increases.

\subsection{Identifying peak usage}

To test the 'identifying peak usage' strategy the water use data was analysed to determine if a garden watering cycle could be identified. Assuming that garden watering followed a weekly cycle, the daily water use data

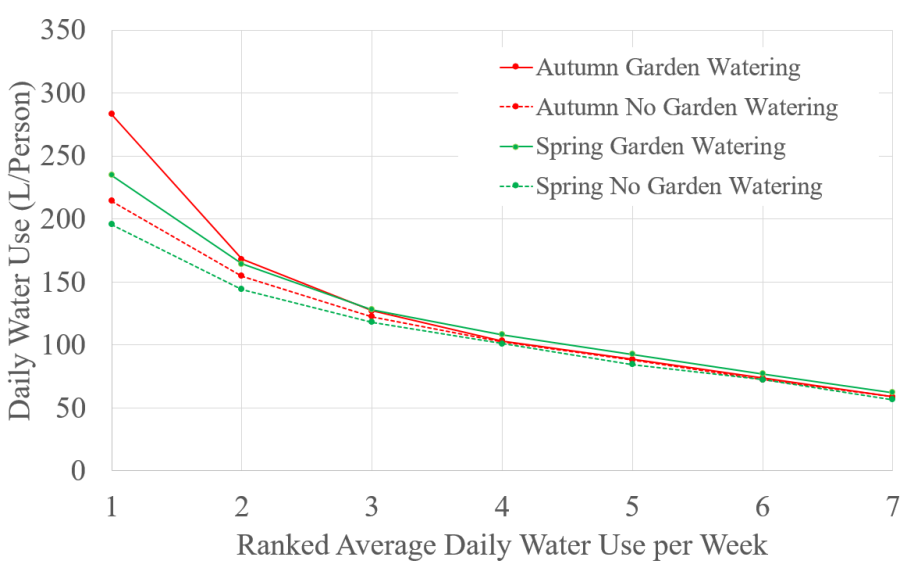

Figure 3. Spring and autumn ranked daily water use averages per week.
Interestingly the process of creating Table 4 did reveal that the standard deviation when observing the range of average water use values from individual properties with garden watering increased with strong consistency as the length of the dry period increase, while the standard deviation from properties without garden watering do not (see Table 5).
ith garden watering becomes increasingly from each property was divided into weeks with the water use total from every day ranked against the other totals within the week (with rank 1 being the highest daily water use for the week and rank 7 being the lowest). From this calculation the average daily water use for each weekly rank could be found for each property and these were averaged to calculate the overall average and standard deviation for water use per property for each rank. Any week with incomplete data was removed from the analysis, with new weeks beginning on Monday to avoid splitting weekend water use across two weeks.

The initial analysis revealed only slight differences between the average water use from properties with and without garden watering across the different weekly ranks. However when this process was repeated upon a seasonal basis it became clear that the increased water demand from gardening in spring and autumn was being masked by an opposite trend during summer and winter. 
Leonard and Gato-Trinidad, Modelling household water use: Using empirical data to inform continuous simulation

From Figure 3 it can be seen that during autumn properties with garden watering used 68.9 L per person more water during $1^{\text {st }}$ ranked days and 13.2 L per person more during $2^{\text {nd }}$ ranked days. During spring properties with garden watering used $39.3 \mathrm{~L}$ per person more water during $1^{\text {st }}$ ranked days and $20.0 \mathrm{~L}$ per person more during $2^{\text {nd }}$ ranked days.

Water use during summer and winter (Figure 4) had noticeably lower water use from properties with garden watering across all of the ranked days. The lack of garden watering during winter was anticipated, but summer is traditionally recognised as a period of peak garden watering

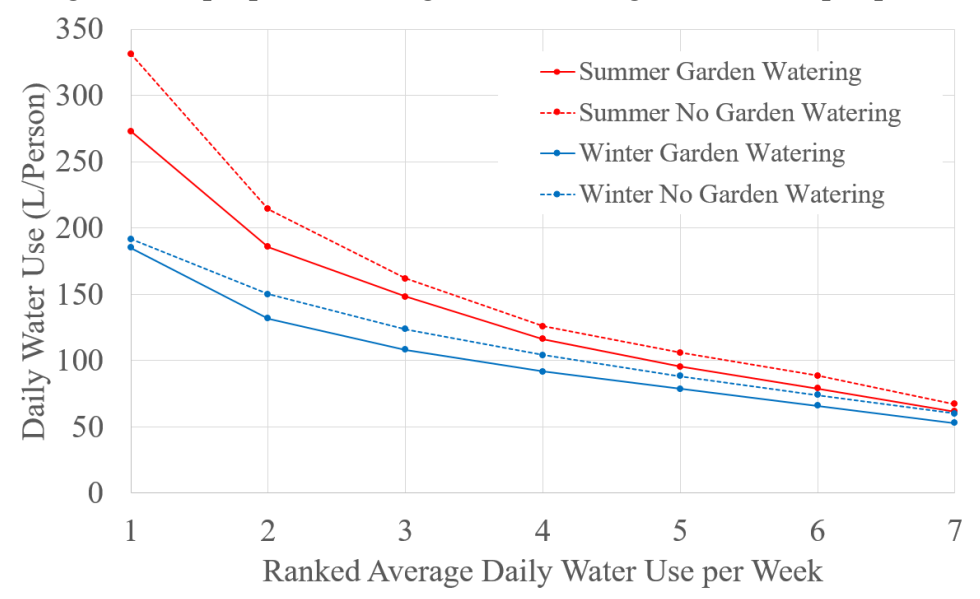

Figure 4. Summer and winter ranked daily water use averages per week. use. This may have been influenced by unusually wet summers during this period (Bureau of Meteorology 2019) or by different properties being involved in the metered study during different seasons.

Table 9. Standard deviation of seasonal ranked daily water use averages per week.

$$
\text { Weekly Ranked Water Use Seasonal Variation }
$$
(L/Person/Day)

\begin{tabular}{lrrrrrrr} 
Sub Category & 1 & 2 & 3 & 4 & 5 & 6 & 7 \\
\hline Summer & & & & & & & \\
Gardening & 296.8 & 174.5 & 142.3 & 83.6 & 69.4 & 55.4 & 41.0 \\
No Gardening & 351.0 & 179.2 & 96.1 & 69.3 & 60.9 & 53.2 & 44.4 \\
Autumn & & & & & & & \\
Gardening & 420.7 & 153.6 & 89.3 & 61.0 & 52.6 & 45.8 & 38.9 \\
No Gardening & 138.5 & 84.7 & 66.9 & 60.9 & 56.3 & 52.5 & 48.6 \\
Winter & & & & & & & \\
Gardening & 109.3 & 81.8 & 69.7 & 59.4 & 51.6 & 45.7 & 39.1 \\
No Gardening & 64.1 & 54.9 & 46.1 & 44.1 & 40.1 & 35.3 & 29.1 \\
Spring & & & & & & & \\
Gardening & 216.5 & 140.9 & 72.5 & 59.1 & 50.1 & 40.2 & 36.1 \\
No Gardening & 69.1 & 51.1 & 47.1 & 41.8 & 37.1 & 32.6 & 28.6 \\
\hline
\end{tabular}

During all seasons Saturday had the highest proportion of highest weekly water use values, accounting for $18 \%$ to $26 \%$ of all first ranked rainfall events. The second most common days were Sunday during spring and summer and Monday during autumn. Winter saw a tie between Sunday and Monday for the second most common day for high water use.

These findings were then compared against the contents of the YVW water use survey in which $2 / 3$ of the properties with gardens claimed to water them once or twice a week while $16 \%$ claimed to water daily. The daily watering claims would explain the consistent separation between the values seen at the lower ranked days of Figure 3 while the twice a week garden watering is also reflected in the greater separation for rank 1 and 2 values. Unfortunately the survey did not question the households regarding the possible seasonal patterns in their garden watering.

\section{CONCLUSION}

Each of the strategies examined in this study had different combinations of strengths and weakness and while the 'lowest average water use' and 'identifying peak water use' strategies demonstrated the most promise, no one strategy was perfect or ideal. The 'lowest average water use' strategy showed that outdoor water use and garden watering both display seasonal trends that can be used to separate the end uses for water if indoor water use is assumed to be constant. This strategy was fast and easy to use but its assumptions could be considered overly simplistic. The 'wet or dry averages' and 'consecutive dry days' strategies showed that total water use is affected by the length of time since the last rainfall. However the analysis also showed that either some outdoor water use does occur on days with rainfall or indoor water use is less consistent than has been assumed. These strategies would be useful in situations where the estimation of water use on each day was more important that the estimation of an overall average. Finally the 'identifying peak usage' strategy demonstrated that garden watering follows both weekly and seasonal patterns, with most properties only watering their gardens a few times a week and only during some seasons. This is probably the most realistic assessment of the garden watering water use patterns, but is also the most difficult of the four assessments to undertake.

It is hoped that these insights will prove useful to researchers who are considering which method is best suited for representing outdoor water use or gardening within their own continuous simulations. The next step in this 
Leonard and Gato-Trinidad, Modelling household water use: Using empirical data to inform continuous simulation

study would be to repeat these analysis upon properties with monitored end uses for water. This would allow many of the assumptions and conclusions that have been inferred from this data to be directly tested.

\section{ACKNOWLEDGMENTS}

The authors wish to thank Yarra Valley Water for allowing the use of their data in the creation of this paper.

The authors are grateful for the ongoing support of the "Australian Government Research Training Program Scholarship".

\section{REFERENCES}

Akan, A. (1985). Kinematic-wave method for peak runoff estimates. Journal of Transport Engineering, 111(4), 419-425.

Amos, C.C., Rahman, A. and Gathenya, J.M. (2016). Economic analysis and feasibility of rainwater harvesting systems in urban and peri-urban environments: a review of the global situation with a special focus on Australia and Kenya. Water 2016, 8(4), 1-21.

Amos, C.C., Rahman, A. and Gathenya, J.M. (2018). Economic analysis of rainwater harvesting systems comparing developing and developed countries: a case study of Australia and Kenya. Journal of Cleaner Production, 172, 196-207.

Bradford, A., Pentelow, S. and Denich, C. (2008). Matching rainwater harvesting strategies with ecological flow needs. International Low Impact Development Conference 2008, ASCE, Seattle, Washington, November 16-19.

Bureau of Meteorology (2019). Climate data online, Australian Government Bureau of Meteorology, viewed 15/05/2019, http://www.bom.gov.au/climate/data/

Burns, M.J. and Mitchell, V.G. (2008). Stormwater harvesting: assessing operational system performance. Australian Journal of Water Resources, 12(2), 153-160.

Burns, M., Fletcher, T., Duncan, H., Hatt, B., Ladson, A. and Walsh, C. (2012). The stormwater retention performance of rainwater tanks at the land-parcel scale. 7th international WSUD conference, EA, Melbourne, Australia, February 21-23.

Campisano, A., Butler, D., Ward, S., Burns, M.J., Friedler, E., DeBusk, K., Fisher-Jeffes, L.N., Ghisi, E., Rahman, A., Furumai, H. and Han, M. (2017). Urban rainwater harvesting systems: research, implementation and future perspectives. Water Research, 115, 195-209.

Coombes, P., Bethke, K., Cullen, A., Allan, A., Comley, J. and Pamminger, F. (2011). A water smart plan for Doncaster Hill- transforming a principal activity centre into a key component of a sustainable city. Planning Institute of Australia National Conference, PIA, Coolum, Australia.

Gato, S., Niranjali, J. and Roberts, P. (2007). Temperature and rainfall thresholds for base use urban water demand modelling. Journal of Hydrology, 337(3-4), 364-376.

Gato-Trinidad, S., Jayasuriya, N. and Roberts, P. (2011). Understanding urban residential end uses of water. Water Science \& Technology, 64(1), 36-42.

Gold, A., Goo, R., Hair, L. and Arazan, N. (2010). Rainwater harvesting: policies, programs, and practices for water supply sustainability. Low Impact Development 2010: Redefining Water in the City, ASCE, San Francisco, California, April 11-14.

Jensen, M.A., Steffen, J., Burian, S.J. and Pomeroy, S. (2010). Do rainwater harvesting objectives of water supply and stormwater management conflict?. Low Impact Development International Conference (LID) 2010, ASCE, San Francisco, California, April 11-14.

Knights, D., Hanley, C. and McAuley, A. (2012). Can rainwater tanks meet multiple sustainability objectives? an assessment of water conservation, pollution reduction and frequent flows from rainwater tanks in Sydney. $7^{\text {th }}$ International Conference on Water Sensitive Urban Design, Melbourne, Australia, February 21-23.

Roebuck, R.M. and Ashley, R.M. (2006). Predicting the hydraulic and life-cycle cost performance of rainwater harvesting systems using a computer based modelling tool. $7^{\text {th }}$ International Conference on Urban Drainage Modelling and the $4^{\text {th }}$ International Conference on Water Sensitive Urban Design: Book Proceedings, EA: Monash University, Melbourne, Victoria, Australia, April 2-7. 